\title{
A Study of Speed of Sound in Water
}

\author{
Anuj Kumar ${ }^{2}$, P.P.Pathak ${ }^{2}$ and N.Dass ${ }^{1}$ \\ ${ }^{1}$ Physics Department, College of Engineering Roorkee, Roorkee, zip-247667 \\ ${ }^{2}$ Physics Department, Gurukul Kangari Vishwavidyalaya, Haridwar
}

\begin{abstract}
In the present paper, two-state theory of water is applied to study the temperature dependence of speed of sound. The computed results are found in good agreement with experimental data. The theory also predicts a thermal maximum in speed of sound near $76^{\circ} \mathrm{C}$ which matches with the experimental value.
\end{abstract}

Keyword: Water, speed of sound, Temperature and Two-state theory

\section{Introduction}

The study of speed of sound in liquids is an important property from theoretical as well from practical point of view due to the fact that it can provide some thermo-dynamical properties of liquids. The study of sound speed in water becomes still more important due to fact that it exhibits a maximum near $76^{\circ} \mathrm{C}$.

Some empirical relations [1-4] are available in literature to study the speed of sound in water as a function of temperature but no model or theory is available so far. Though, a model [5-6] is available to study the pressure dependence of speed of sound in liquids. Therefore, the aim of present paper is to study the temperature dependence of speed of sound in water based on two-state theory.

According to two-state theory[7], water is considered as a mixture of two species- one specie is called open-packed specie resembling with ice structure and the second is called close-packed specie resembling with un-hydrogen bonded water molecules. Both the species are in equilibrium at all temperatures. Mole fraction of open-packed specie will decrease with the rise in temperature due the braking of bonds while the mole fraction of close-packed specie will increase.

Some physical properties of water studied successfully on two-state theory are (i) ultrasonic absorption [8], (ii) NMR shift [9], refractive index [10], dielectric constant [11] and viscosity [12]

\section{Theory}

To study the temperature dependence of speed of sound in water based on two-state theory, we write the relation as

$$
\mathrm{V}=\mathrm{X}_{0} \mathrm{~V}_{0}+\mathrm{X}_{\mathrm{C}} \mathrm{V}_{\mathrm{C}}
$$

Where $\mathrm{X}_{0}$ and $\mathrm{V}_{0}$ represent the mole fraction and speed of sound of open-packed specie, respectively, whereas $\mathrm{X}_{\mathrm{C}}$ and $\mathrm{V}_{\mathrm{C}}$ are the same quantities for close-packed specie. Further, to obtain the values of $\mathrm{V}_{0}$ and $\mathrm{V}_{\mathrm{C}}$, we write the relations as

$$
\begin{aligned}
& \mathrm{V}_{0}=\mathrm{A}+(\mathrm{B} / \mathrm{T}) \\
& \mathrm{V}_{\mathrm{C}}=\mathrm{C}+(\mathrm{D} / \mathrm{T})
\end{aligned}
$$

Where A, B, C and D are temperature independent parameters and $\mathrm{T}$ is in $\mathrm{K}$. Thus, eq. (1) can be expressed as

$$
\mathrm{V}=\mathrm{X}_{0}[\mathrm{~A}+(\mathrm{B} / \mathrm{T})]+\left(1-\mathrm{X}_{0}\right)[\mathrm{C}+(\mathrm{D} / \mathrm{T})]
$$

Where

$$
\mathrm{X}_{0}+\mathrm{X}_{\mathrm{C}}=1
$$

It is clear that once the values of $X_{0}$ and $T$ become known, one can compute the values of speed of sound in water by obtaining the values of $\mathrm{A}, \mathrm{B}, \mathrm{C}$ and $\mathrm{D}$ by least square fitting.

But, Davis and Litovitz [7] have reported the values of $\mathrm{X}_{0}$ in the temperature range of 0- $100{ }^{\circ} \mathrm{C}$ at an interval of $10{ }^{\circ} \mathrm{C}$. But, the values of $\mathrm{X}_{0}$ are required at the interval of $5{ }^{\circ} \mathrm{C}$ to study the temperature dependence of speed of sound in water. Therefore, an empirical relation is developed to study the temperature dependence of $\mathrm{X}_{0}$ as

$$
\mathrm{X}_{0}=0.637-0.6668\left[1-\exp \left(-6.8328 \times 10^{-3} \mathrm{t}\right)\right]
$$

Where $\mathrm{t}$ is in ${ }^{0} \mathrm{C}$. The standard deviation obtained is 0.0016 .

\section{Calculations and Discussions}

Knowing the values of $\mathrm{X}_{0}$ and $\mathrm{T}$, eq(4) is used to obtain the values of $\mathrm{A}, \mathrm{B}, \mathrm{C}$ and $\mathrm{D}$ by least square fit. The values of $\mathrm{A}, \mathrm{B}, \mathrm{C}$ and $\mathrm{D}$ along with the values of $\mathrm{V}, \mathrm{V}_{0}$ and $\mathrm{V}_{\mathrm{C}}$ are reported in Table 2 . A comparison between the computed values and the experimental data is also reported in Fig 1. It is evident from Table 2 and Fig 1 that the computed values of speed of sound in water exhibits a thermal maximum near $75^{\circ} \mathrm{C}$ whereas the 
experimental value of thermal maximum is $76{ }^{\circ} \mathrm{C}$. Thus, it may be said that a very good agreement exits between the computed values and the experimental data of speed of sound in water as the standard deviation obtained is $0.75 \mathrm{~m} / \mathrm{s}$.

Further, it is evident from Table 2 that the value of $V_{0}$ is increasing whereas the value of $V_{C}$ is decreasing with rise in temperature and this might has given a maximum.

Table 1 Comparison of values of $\mathrm{X} 0$ with temperature in water

\begin{tabular}{|c|c|c|c|c|c|}
\hline Temp. $\left({ }^{\circ} \mathrm{C}\right)$ & $\mathrm{X}_{0}[7]$ & $\mathrm{X}_{0}$ Calc. & Temp. $\left({ }^{\circ} \mathrm{C}\right)$ & $\mathrm{X}_{0}[7]$ & $\mathrm{X}_{0}$ Calc. \\
\hline 0 & 0.637 & 0.637 & 55 & ---- & 0.428 \\
\hline 5 & ---- & 0.615 & 60 & 0.411 & 0.143 \\
\hline 10 & 0.595 & 0.593 & 65 & --- & 0.398 \\
\hline 15 & ---- & 0.572 & 70 & 0.382 & 0.383 \\
\hline 20 & 0.554 & 0.552 & 75 & --- & 0.370 \\
\hline 25 & --- & 0.532 & 80 & 0.355 & 0.359 \\
\hline 30 & 0.515 & 0.513 & 85 & --- & 0.343 \\
\hline 35 & ---- & 0.495 & 90 & 0.331 & 0.331 \\
\hline 40 & 0.478 & 0.477 & 95 & ---- & 0.319 \\
\hline 45 & ---- & 0.460 & 100 & 0.309 & 0.307 \\
\hline 50 & 0.443 & 0.444 & --- & --- & --- \\
\hline
\end{tabular}

Table 2. Comparison of speed of sound $(\mathrm{m} / \mathrm{s})$ in water along with the values of $\mathrm{V} 0$ and $\mathrm{VC}$

\begin{tabular}{|l|l|l|l|l|}
\hline TEMP. $\left({ }^{\circ} \mathrm{C}\right)$ & $\mathrm{V}_{0}$ & $\mathrm{~V}_{\mathrm{C}}$ & $\mathrm{V}$ (Calc.) & $\mathrm{V}$ (Exptl.) \\
\hline 0 & 1051.88 & 2017.80 & 1402.55 & 1402.74 \\
\hline 5 & 1072.69 & 1991.52 & 1426.47 & 1426.60 \\
\hline 10 & 1092.76 & 1966.18 & 1446.53 & 1447.59 \\
\hline 15 & 1112.13 & 1941.71 & 1467.22 & 1466.25 \\
\hline 20 & 1130.85 & 1918.08 & 1481.98 & 1482.66 \\
\hline 25 & 1148.93 & 1895.24 & 1498.23 & 1497.00 \\
\hline 30 & 1166.42 & 1873.15 & 1509.21 & 1509.44 \\
\hline 35 & 1183.34 & 1851.78 & 1520.93 & 1520.12 \\
\hline 40 & 1199.72 & 1831.10 & 1529.32 & 1529.18 \\
\hline 45 & 1215.59 & 1811.06 & 1537.17 & 1536.72 \\
\hline 50 & 1230.96 & 1791.65 & 1543.29 & 1542.87 \\
\hline 55 & 1245.86 & 1772.82 & 1547.31 & 1547.70 \\
\hline 60 & 1260.32 & 1754.57 & 1551.45 & 1551.30 \\
\hline 65 & 1274.35 & 1736.85 & 1552.80 & 1553.76 \\
\hline 70 & 1287.97 & 1719.65 & 1554.77 & 1555.12 \\
\hline 75 & 1301.20 & 1702.94 & 1554.32 & 1555.45 \\
\hline 80 & 1314.05 & 1686.71 & 1554.43 & 1554.81 \\
\hline 85 & 1326.55 & 1670.93 & 1552.82 & 1553.25 \\
\hline 90 & 1338.70 & 1655.58 & 1550.71 & 1550.79 \\
\hline 95 & 1352.45 & 1640.65 & 1548.12 & 1547.50 \\
\hline 100 & 1362.02 & 1626.13 & 1544.53 & 1543.41 \\
\hline
\end{tabular}

$\mathrm{A}=2.2087 \mathrm{e}+03 \quad \mathrm{~B}=-3.1581 \mathrm{e}+05$

$\mathrm{C}=5.5685 \mathrm{e}+02 \quad \mathrm{D}=3.9884 \mathrm{e}+05$

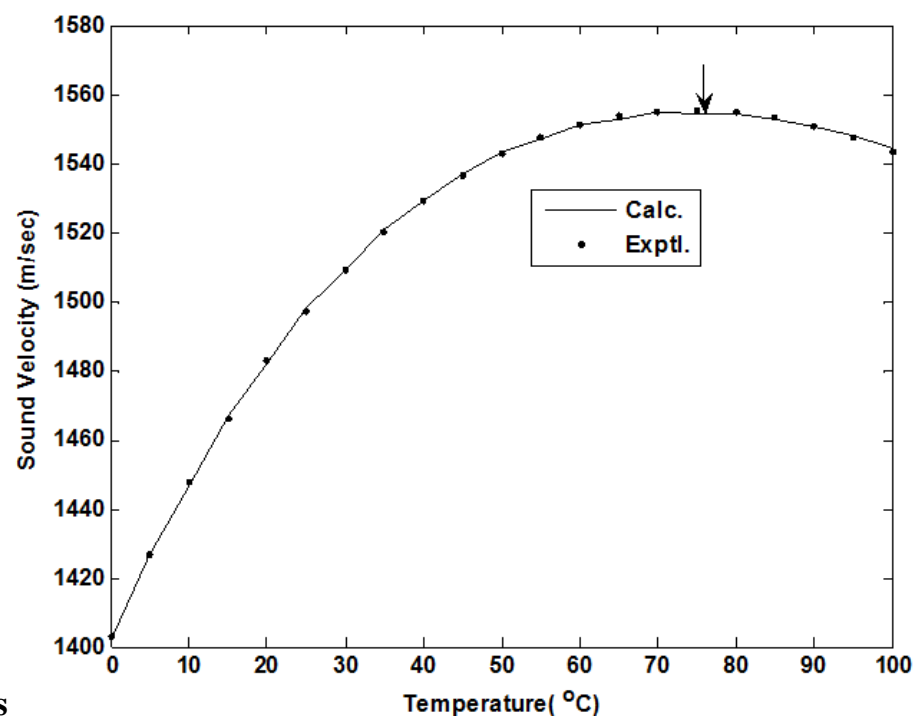

Fig. 1: Variation of sound velocity with temperature 


\section{References}

[1] G.W. Willard,Temperature coefficient of ultrasonic velocity in solutions, J. Acous. Soc. Am. 19, 235 (1947)

[2] R.A. McConell and W.F. Mruk,Microacoustic interferometer using 30-MC Pulses, J. Acous. Soc. Am. 27, 672 (1955)

[3] M. Greenspan and E. Tschiegg,Tables of speed of sound in water, J. Acous. Soc. Am. 31, 75 (1959)

[4] A.J. Barlow and E. Yazgan, Brit. J. Appl. Phys. 18, 645 (1967)

[5] R. Kumar, P. Kuchhal and N. Dass, The pressure and temperature dependence of the velocity of sound in liquid metals, J. Phys.: Condens. Matter 8,10891 (1996)

[6] A. Kumar, P. Kuchhal, N. Dass and P.P. Pathak, Anomalous behavior in sound velocity of water,Phys Chem Liquids

49,453 (2011)

[7] C.M. Davis and T.A. Litovitz,Two-state theory of the structure of water, J. Chem. Phys. 42, 2563 (1965)

[8] L. Hall,The origin of ultrasonic absorption in water, Phys. Rev. 73, 775 (1948)

[9] N. Muller,Concerning structural models for water and chemical shift data, J. Chem. Phys. 43, 2555 (1965)

[10] S.K. Mitra, N. Dass and N.C. Varshneya,Temperature dependence of the refractive index of water, J. Chem. Phys. 57, $1798,1972$.

[11] N. Dass,Temperature dependence of dielectric constant in light and heavy water, Phys. Chem. Liquids 15, 323 (1986)

[12] C.H. Cho, J. Urquidi and G.W. Robinson,Molecular-level description of temperature and pressure effects on the viscosity of water , J. Chem. Phys. 111,10171(1999). 